\title{
Specificities of using information technologies in agriculture construction management
}

\author{
Sergey Sinenko, ${ }^{1, *}$ and Ivan Doroshin ${ }^{1}$ \\ ${ }^{1}$ Moscow State University of Civil Engineering, Yaroslavskoye shosse 26, 129337, Moscow, Russia
}

\begin{abstract}
In this paper, the singularities of using information technologies in organization and management of agriculture construction are considered. The main components of information technologies in investment projects are very important for agriculture construction. The most important computer programs for comparative analysis of investment projects are considered. Also, the complex decisions integrating all the parts of construction design for agriculture buildings are described. The purpose of the research is estimation of possibility of using information technologies in construction, allowing maximally automatizing design and calculation works. For carrying out the stud,y the methodical and scientific literature on the subject was analyzed, and also the statistic methods of data investigation were used considering the use of information technologies in different construction companies. The main result of the research is comparative analysis of modern information technologies in organization of construction and estimation of their effectiveness.
\end{abstract}

\section{Introduction}

Erection of the capital construction objects implies using the information technologies in construction management. The construction projects are rather big, from the point of view of information resources, the data about construction objects are usually stored in separated information systems. That creates a whole row of serious problems, for example:

1. The detailing of planning of the whole project is excessively difficult and often impossible.

2. The composing and coordination of project-estimate documentation is increased in such extent, that the final version is created during the construction begun.

3. The coordination of contractor actions, and also the operative controlling from the customer side are difficult or impossible.

4. The analysis of variation reasons of the actual progress of construction from the plan is impossible, to make corrections and eliminate the delay is unreal [1-5].

As a result:

1. Unreality of the project budget.

2. The increase of time of performance and project expenses.

3. The contradiction of reports to the real state of business. [6-10].

* Corresponding author: ivandoroshin@rambler.ru 
The specificities and the difficulty of realization of investment projects in construction demand using of information technologies, which let automatize maximally the design and calculation works, thus saving the time and the results of human labor.

The information technologies represent a combination of procedures, realizing the functions of obtaining, accumulation, storing, treatment, analysis and transition of information in the organization structure, using the means of computer facilities and the communication means.

The information technologies in investment projects are usually represented by the next main components:

- computer facilities and peripheral devices;

- program supplement, including specialized, in particular intended for the investment calculations;

- communication means [11-15].

\section{Methods}

For this research, the methodical and scientific issues on the subject were analyzed, and also the statistic methods of data investigation were used considering the experiment of work with different computer means in different construction companies.

\section{Results}

Nowadays, on the Russian market, there are hundreds of computer programs for the calculation and comparative analysis of investment projects, both domestic and foreign.

The investment projects have different types of expenses, that are usually paid on certain stages of the life-cycle of the project, as shown in Fig.1

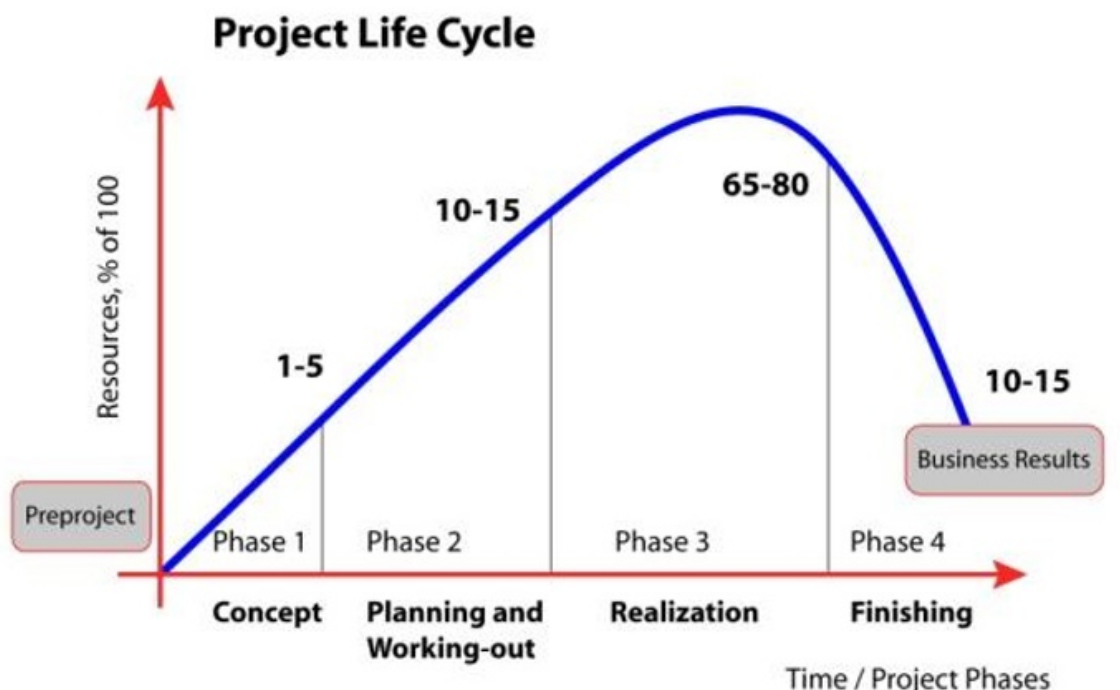

Fig. 1. Stages of investment project.

Between the foreign programs, it is necessary to mark COMFAR and PROPSPIN, that has been created in UNIDO - the committee of industrial development at UN. Trello for the management of task flows (customs, preparing of commercial proposals, management of 
narrow resources). Oracle Primavera for the work in large and unique projects, demanding management by the critical path method. Working on the certain parts of an investment project, it is necessary to remember, that the Preproject phase is also very important and must be carefully analysed. The cost of preproject works may follow the dependence shown in Fig.2

Between the domestic we may mention the "Project Expert" of the "PRO-INVEST CONSULTING" firm, "Investor" and "Analitik" of the "INEK" firm, "TEO-INVEST" of the Institute of management problems of the Russian Academy of Sciences, "IKS: Upravlenie stroitelstvom" that has been created on the basis of the typical configuration 1S:Accounting and contains all its elements. The configuration is intended for use in enterprises of the next profile: construction and installation, repair-operational, laying of communication lines, power supply, gasification, heating, water supply, road-transport and others, where the project-estimate documentation is used. In the basis of working out the conception of supremacy of the Resource estimate in the activity of contractor construction organization is taken.

\section{Dependence of rate on investigation works from the height and area of building}

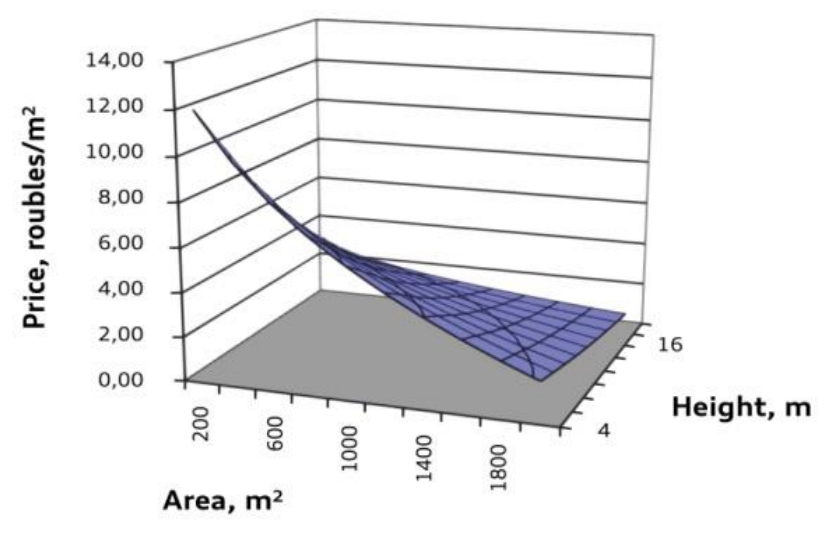

Fig. 2. Cost of preproject works.

The estimate may be formed using such estimate programs as "Bars", "Smeta-2000", "Resursnaya smeta" etc. or form manually, that is the basis for automatic formation of all the further actions: planning, account and analysis. Such architecture of program simplifies and relieves greatly the work of engineering-technical personal, accountants and administration of the enterprise. Comparing the real expenses for works and materials with the prices in estimate, it is possible to analyze the activity of the enterprise on each stage of construction, to prevent unauthorized actions: for example, customs of materials, work accomplishment, exploitation of tools and devices. The product given will help to decide one of the main tasks of contractor organization - the decreasing of construction expenses.

The program products given may be divided into two types. To the first we may relate the "TEO-INVEST" - the programs work on the basis of MS-Excel. All the rest programs from the aforesaid we may relate to the second type - they work independently, without using of other program means. Such approaches to the creation of program supplement have their advantages and drawbacks.

In the case of using as the basis of MS Excel, there can be used the powerful calculation and graphic possibilities of this program product. Though this approach confines the 
autonomy of specialized program supplement and functionality of the MS Excel possibilities. Using MS Excel, we may obtain the next curve for cash flow of project, as shown in Fig.3

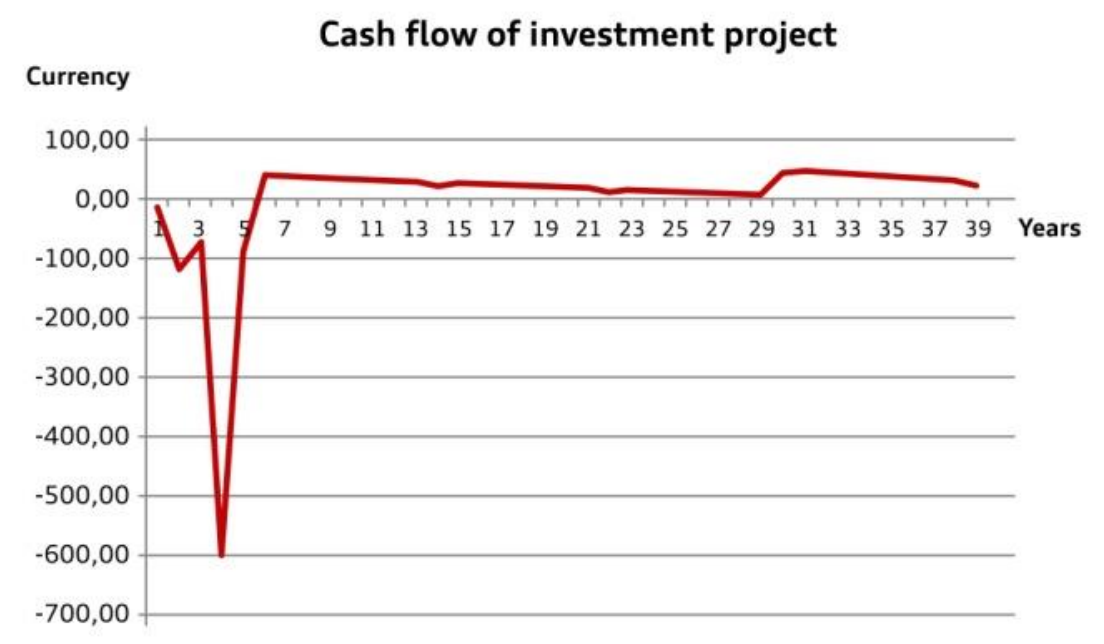

Fig. 3. Income of investment project.

The second type programs have greater flexibility, independence and usually functionality. But in the same time they demand also considerably greater expenses for working out and by several parameters still lose to the programs, built on the basis of MS Excel.

Using the special programs we may highlight the next advantages:

- certain realized methodic of calculation

- reliability;

- $\quad$ ease of results presentation;

- relative time economy;

- enhancement of image of creators of investment project.

To the drawbacks we may relate the next:

- relatively high cost (from 900 to $4500 \$$ );

- decreasing of flexibility;

- fixed data set.

Special program products in project management in construction support the next structure models of project: network project model (hierarchic system of network project models) with the given degree of works detailing; structural decomposition of works, the resources tree; hierarchic system of works coding for obtaining of reports on project model in the necessary sections - on life cycle phases, on responsibilities, on cost items, on geographic sign etc.[6-10].

The information technologies in investment projects in construction automatize and regulate all the activity, connected with the investment construction, that entails:

1. Increase of efficiency of collection and analysis of necessity in investment construction.

2. Optimization and unification of the process of confirmation and changing of plans and budgets of capital construction.

3. Increase of efficiency of investments planning, capital construction at expense of, in particular, analysis of alternative variants of investment realization.

4. Reducing of time of new construction, as much as of reconstruction and modernization of production. 
5. Provision of timely putting into operation of capital assets and production capacities.

6. Establishment of constant supply of construction objects with material, labor and financial resources.

7. Increase of efficiency of control of works accomplishment and timely provision of objects, accuracy of control of budget means on the project.

8. Increase of speed and exactness of formation of operation and industrial reporting for taking of management decisions.

Let us observe, that the information systems in investment projects for construction must present all the necessary tools of analysis and making decisions for specialists, and also:

1. Decide everyday tasks of all the categories of specialists of construction industry from foreman and supplier to financier and head of company.

2. Help to manage all the stages of capital construction - from preliminary choice of objects to the completion of exploitation

3. Suit to companies of different scale and with different business models.

4. Consider regional and industrial differences in building production. [6-10].

Let us discuss the possibilities of using of program projects in management of investment construction projects.

On every step of investment project one of the most important tasks is calculation of expenses, especially tied with the construction of buildings and structures. For this purpose estimate specialists in Russia use different programs, that have different costs and set of bases used. The most important programs have such prices (including the purchase and the service), as shown in Fig.4.

\section{Price, roubles}

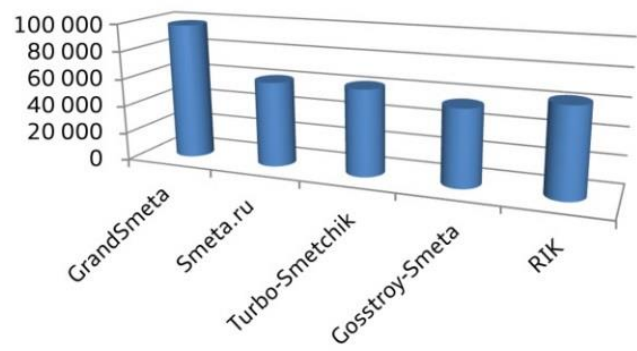

Fig. 4. Prices of estimate programs.

The popularity of these instruments is shown in Fig. 5 The data were taken from the site https://www.all-smety.ru.

\section{Prevalence,\%}
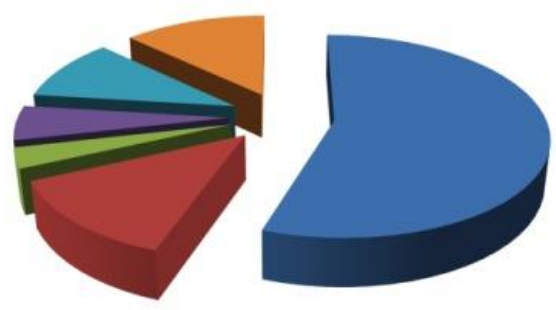

GrandSmeta - 55,3\%

Smeta.ru-12,9\%

Turbo-Smetchik - 3,23\%

Gosstroy-Smeta - 5,53\%

RIK - $10,14 \%$

Other $-12,9 \%$

Fig. 5. Popularity of estimate programs. 
Rather popular in use is the ERP system for construction BauFinancials from Nemetschek Bausoftware, that unifies in one system the technical and commercial aspects of activity of construction corporation and represents the industrial adjustable ERP decision, suggesting universal integration (warehouses, supply, design-technical departments (PTO), finance/economics, estimates, accounts department, construction sites, etc.) That regards both to all the functional departments in commercial and technical fields and to all the organization units of the enterprise (central administration, branch offices, production units, maintenance shops).

The ERP system for construction BauFinancials unifies in one system the technical and commercial aspects of activity of construction corporation and represents the adjustable ERP application.

When using this information system, the data are entered into the computer only once and then are presented in the form of general base for all the integrated applications.

The better is the program supplement covers all the chain of activity types, the greater benefit it brings. Finally, the commonly used database is the condition of actuality of information and of decrease of data excessiveness. The actual information, brought to all the authorized, represents by itself the important factor for successful work of the enterprise. The system BAUfinancials is integrated, that lets enter the document into the computer as possible only once. The user can obtain data quickly from the most different department of the enterprise.

Let's get to considering the next program product, used in investment construction projects - the Allplan system.

The Allplan represents by itself the complex decision, integrating all the parts of construction design: architecture, reinforced concrete constructions, engineering systems of buildings, general plan, construction volumes, cost definition and estimates, metal structures, styling. During the design working out all the program components work on the same project simultaneously, they may see the results of work of each other, fit one for another, and the row of changes apply on the complex project separately.

For the investment projects in construction this program is simple and easy in use - for example, the heat losses for the specialist on construction thermophysics when plans are changed will be recalculated with one pressure of the button, the heating facilities will be reelected and placed again with the second pressure. The architecture model transforms intellectually into the calculated for SCAD, LIRA, the constructive constraints by building codes are considered.

When entering the changes, the constructive volumes will be obtained again with a button pressure, also it's easy to obtain the comparative estimate, where the positions changed are only shown.

At the realization of construction investment projects the important thing is the design of heating systems, ventilation, water supply, water disposal and electrics, that lets create the program product Allklima, working on the platform of AutoCAD from 2008, including LT. Simple servicing, using of intellectual graphic elements, automatic definition of system dimensions and forms of shaped parts, built in transparently for the customer calculations (inc. according construction codes), obtaining of specifications and building of axonometric schemes save maximum of time for the specialists of construction and design companies.

The main singularities of the given program product are:

1. Calculation of heat loss and illumination directly on architectural design.

2. Easy automatic and manual designing of systems of ventilation, heating, water supply, water disposal and electrics.

3. Automatic generation of associative view, perspectives and sections.

4. Clear work on custom view. 
5. Help at designing, simplifying the work: wide database, intellectual symbols, automatic identification of systems, etc.

6. Automatic and visual control of conflicts.

7. Associative and optional title writing.

8. Functions of changing and copying.

9. Presentation in 2D/3D.

10. Intellectual graphic elements with specific properties.

11. Quick making of changes and creation of design variants thanks to centralized change of system properties.

12. Easy checked calculations, inc. by constructive codes.

13. Automatic generation of lists and specifications on State Standard.

14. Different variants of specifications, for example, specification of cutting of boxes, specification of shaped parts with graphic images, calculation reports.

During the use of the technology Allplan for investment projects in construction the next data exchange is realised:

1. Highly productive drawing interfaces $\mathrm{dxf} / \mathrm{dwg} / \mathrm{dgn}$.

2. Interfaces of these producers for heating devices and sanitary equipment.

3. Interfaces of manufacturing (for bending machines with $\mathrm{CNC}$ ) for ventilation canals.

4. Specifications in the Excel format.

It's also necessary to notice, that in large design organizations of the Tula city there exist hierarchically built engineering departments, that carry out calculation of structures. Usually these are the departments with full group of specialists, between which: the main specialist, groups leaders, principal engineers, engineers of different categories, able to decide engineering tasks of any difficulty level, using different methods of calculation. For this category of specialists using of calculation program complexes has become usual long ago. But the newly accepted employees must quickly and properly master them. And with complication of the solved calculation tasks the experienced specialists also need to update periodically their knowledge in this field.

When buying the licensed program supplement from creators, with the price in several thousand dollars, the managers of the organizations-customers of program complexes understand the necessity of training of their personnel of working with this "tool for construction calculations", of learning of all the subtleties of this work and in full extent.

Unfortunately, the specialists, working already with such programs, often had studied them individually, using frequently illegal program supplement, that in several cases has limited possibilities compared to the original program product and is used in fact only in minor part of its possibilities.

The main trait of contemporary building production is multivariance of decisions, connected with design and realization of construction technologies. Development of main components of building production process (materials, technical means and equipment, organization and management forms), the increased requirements to the expenditure of material and labor resources, to the quality of engineering and ecological safety of building production; sudden change of the scale of prices, of cost and wages in conditions of market economy, influence of the often changing conditions from the side of external environment all these factors bring the problem of multivariance to the row of most important problems of increasing of effectiveness of building production.

The singularities and difficulty of realization of investment projects in construction demand using of information technologies, that let automatize maximally the design and calculation works, thus saving time and human labor expenses.

\section{Conclusions}


The information technologies represent a combination of procedures, realizing the functions of obtaining, accumulation, storing, treatment, analysis and transition of information in organization structure using the means of computer facilities and the communication means.

The advantages of use of special information programs of management of construction investment projects are presented by: certain realized calculation methodic, reliability, ease of results presentation, relative time saving, enhancement of image of investment project creators. The drawbacks of using of information technologies in investment construction projects are: relatively high cost (from 900 to $4400 \$$ ), decreasing of flexibility, fixed data set.

\section{References}

1. R.R. Kazaryan, V.A. Khvan, Materials Science Forum 931 MSF, 634-639 (2018)

2. R.R. Kazaryan, MATEC Web of Conferences 265, 07007 (2019)

3. R.R. Kazaryan, V.A. Khvan, MATEC Web of Conferences 196, 04030 (2018)

4. R.R. Kazaryan, V.A. Khvan, E3S Web of Conferences 91, 02008 (2019)

5. R.R. Kazaryan, K. Belyaev, E3S Web of Conferences 91, 02024 (2019)

6. A. Slavin, S. Sinenko, N. Yoshin, IOP Conference Series: Materials Science and Engineering 21, 062040 (2018) https://doi.org/10.1088/1757-899X/365/6/062040

7. S. Sinenko, A. Ahmetgaliev, A. Slavin, IOP Conference Series: Materials Science and Engineering 21, 062039 (2018)

8. S.A. Sinenko, A.O. Feldman, International Multi-Conference on Industrial Engineering and Modern technologies IOP Conf. Series: Materials Science and Engineering 463, 042010 (2018)

9. R.R. Kazaryan, MATEC Web of Conferences 193, 04023 (2018)

10. K.Yu. Losev, V.O. Chulkov, R.R. Kazaryan, IOP Conf. Series: Materials Science and Engineering 463, 032085 (2018) https://doi.org/10.1088/1757-899X/463/3/032085

11. L. Melián-Alzola, M. Fernández-Monroy, M. Hidalgo-Peñate, Tourism Management Perspectives 33, 100606 (2020) https://doi.org/10.1016/j.tmp.2019.100606

12. L. Mivehchi, Procedia Computer Science 158, 508-512 (2019) https://doi.org/10.1016/j.procs.2019.09.082

13. W. Przychodzen, F. Gómez-Bezares, J. Przychodzen, Journal of Cleaner Production 201, 570-579 (2018) https://doi.org/10.1016/j.jclepro.2018.08.081

14. A. Barbu, G. Militaru, Procedia Manufacturing 32, 1069-1076 (2019) https://doi.org/10.1016/j.promfg.2019.02.323

15. W. Zeng, M. Koutny, Journal of Information Security and Applications 49, 102385 (2019) https://doi.org/10.1016/j.jisa.2019.102385 